\title{
Avoiding hospital admission through provision of hospital care at home: a systematic review and meta-analysis of individual patient data
}

\author{
Sasha Shepperd MSc DPhil, Helen Doll MSc DPhil, Robert M. Angus MBChB, Mike J. Clarke MA DPhil, \\ Steve Iliffe BSc MBBS, Lalit Kalra MD PhD, Nicoletta Aimonio Ricauda MD, Vittoria Tibaldi MD PhD, \\ Andrew D. Wilson MD
}

$\infty$ See related commentary by Leff, page 156

\section{ABSTRACT}

Background: Avoidance of admission through provision of hospital care at home is a scheme whereby health care professionals provide active treatment in the patient's home for a condition that would otherwise require inpatient treatment in an acute care hospital. We sought to compare the effectiveness of this method of caring for patients with that type of in-hospital care.

Methods: We searched the MEDLINE, EMBASE, CINAHL and EconLit databases and the Cochrane Effective Practice and Organisation of Care Group register from the earliest date in each database until January 2008. We included randomized controlled trials that evaluated a service providing an alternative to admission to an acute care hospital. We excluded trials in which the program did not offer a substitute for inpatient care. We performed meta-analyses for trials for which the study populations had similar characteristics and for which common outcomes had been measured.

Results: We included 10 randomized trials (with a total of 1327 patients) in our systematic review. Seven of these trials (with a total of 969 patients) were deemed eligible for metaanalysis of individual patient data, but we were able to obtain data for only 5 of these trials (with a total of 844 patients [87\%]). There was no significant difference in mortality at 3 months for patients who received hospital care at home (adjusted hazard ratio [HR] 0.77, 95\% confidence interval [CI] $0.54-1.09, p=0.15)$. However, at 6 months, mortality was significantly lower for these patients (adjusted HR $0.62,95 \% \mathrm{CI}$ $0.45-0.87, p=0.005$ ). Admissions to hospital were greater, but not significantly so, for patients receiving hospital care at home (adjusted HR 1.49, 95\% Cl 0.96-2.33, $p=0.08$ ). Patients receiving hospital care at home reported greater satisfaction than those receiving inpatient care. These programs were less expensive than admission to an acute care hospital ward when the analysis was restricted to treatment actually received and when the costs of informal care were excluded.

Interpretation: For selected patients, avoiding admission through provision of hospital care at home yielded similar outcomes to inpatient care, at a similar or lower cost.

Une version française de ce résumé est disponible à l'adresse www.cmaj.ca/cgi/content/full/180/2/175/DC1

CMAJ 2009;180(2):175-82
$\mathrm{I}$ n many countries, programs in which hospital care is provided in the patient's own home continue to be a popular response to the increasing demand for acute care hospital beds. Patients who received care through such programs, after assessment in the community by their primary care physician or in the emergency department, may avoid admission to an acute care ward. Alternatively, patients may be discharged early from hospital to receive hospital care at home. We have conducted a parallel systematic review and meta-analysis of individual patient data related to hospital care at home for patients who have received early discharge, which we will report separately. Recently, the emphasis has been on avoiding admission to hospital, which reflects the relatively limited gain from discharging patients early after a stay in hospital, given the universal trend for shorter lengths of stay in hospital.

The types of patients receiving hospital care at home differ among schemes, as does the use of technology. Some schemes are designed to care for patients with specific conditions, such as chronic obstructive pulmonary disease, or to provide specific skills, such as parenteral nutrition. However, many schemes for the provision of hospital care at home lack such clear functions and have an "open door" policy covering a wide range of conditions. These schemes may build on existing community resources, or they may operate as hospital outreach services, with hospital staff making home visits. In particular, "hospital-at-home" programs are defined by the provision, in patients' own homes and for a limited period, of a specific service that requires active participation by health care professionals. The care tends to be multidisciplinary and may include technical services, such as intravenous services.

Cutting costs by avoiding admission to hospital altogether is the central goal of such schemes. Other perceived benefits

From the Department of Public Health (Shepperd, Doll), University of Oxford, Oxford; Aintree Chest Centre (Angus), Aintree University Hospitals NHS Foundation Trust, Liverpool; UK Cochrane Centre (Clarke), Oxford; Department of Primary Care and Population Health (Iliffe), University College London, London; Department of Medicine (Kalra), Guy's, King's \& St Thomas' School of Medicine, London, UK; Department of Medical and Surgical Disciplines (Aimonino Ricauda, Tibaldi), S. Giovanni Battista Hospital, University of Torino, Torino, Italy; and the Department of Health Sciences (Wilson), University of Leicester, Leicester, UK 
include reducing the risk of adverse events associated with time in hospital ${ }^{1}$ and the potential benefit of receiving rehabilitation in the home environment. However, it is not known if patients covered by a policy of avoiding admission through the provision of hospital care at home have health outcomes better than or equivalent to those of patients who receive inpatient hospital care. Furthermore, it is not known if the provision of hospital care at home results in a reduction or an increase in costs to the health service. We conducted a systematic review and meta-analysis, using individual patient data and published data, to determine the effectiveness and cost of managing care of patients through the provision of hospital care at home relative to inpatient hospital care. The meta-analysis of individual patient data allowed us to investigate whether the strategies were associated with key events happening after different periods of time, rather than simply whether or not those events occurred.

\section{Methods}

We conducted this review according to methods recommended by the Cochrane Effective Practice and Organisation of Care review group (www.epoc.cochrane.org/en/index .html). The full review has recently been published in The Cochrane Library. ${ }^{2}$

\section{Data sources}

To identify relevant studies in all languages, we searched the following databases from the earliest date in each database to January 2008: MEDLINE, EMBASE, CINAHL, EconLit and the Cochrane Effective Practice and Organisation of Care Group register. The search strategy is available in Appendix 1 (available at www.cmaj.ca/cgi/content/full/180/2/175/DC2). We checked the reference lists of articles identified for additional evaluations of hospital-at-home programs and obtained complete copies of potentially relevant articles. We sought unpublished studies by contacting providers and researchers known to be involved in this field.

\section{Study selection}

We included randomized controlled trials that compared programs aimed at avoidance of admission through provision of hospital care at home with inpatient care in acute care hospitals for patients aged 18 years and older. We included studies in which patients entered the program directly from the community, thereby avoiding physical contact with the hospital, or from the emergency department. We used the following definition to determine if studies should be included in the review: a hospital-at-home program is a service that can avoid the need for hospital admission through the provision of active treatment (but not long-term care) by health care professionals in the patient's home for a condition that otherwise would require inpatient care in an acute care hospital. If the program offering hospital care at home were not available, the patient would be admitted to an acute care ward. We excluded interventions involving long-term care; services provided in outpatient settings or after discharge from hospital; and self-care by the patient in his or her home, such as self- administration of an intravenous infusion. We also excluded from this review evaluations of schemes for provision of hospital care at home to obstetric, pediatric and mental health patients, since our preliminary literature searches revealed substantial differences between the patient groups and a large volume of literature, both of which suggested that separate reviews would be justified for each of these groups.,4

\section{Outcomes}

The outcomes of interest were mortality, readmissions or transfers to hospital for those requiring inpatient care while they were receiving hospital care at home, general and disease-specific health status, functional status, psychological well-being, clinical complications, patient and caregiver satisfaction, caregiver burden, staff perspectives (including satisfaction of general practitioners), place of residence at followup, length of stay in hospital (if applicable) and in the hospital-at-home program, and cost to the patient and family and to the health service.

\section{Quality assessment and data extraction}

One author (S.S.) read all of the abstracts in the records retrieved by the electronic searches to identify publications that might be eligible for this review. Two authors (S.S. and S.I.) then independently read the 67 publications identified by this process and selected studies for the review according to the prespecified inclusion criteria. There was initial uncertainty over the inclusion of one trial, ${ }^{5}$ and it was excluded following discussion by these 2 authors. We assessed the quality of eligible trials using the following criteria: concealment of allocation, blinded assessment of outcomes, follow-up of patients, measurement of baseline data, use of reliable outcome measures (objective measures or measures known to be reliable and valid) and protection against contamination of the intervention and control groups. The same 2 authors (S.S. and S.I.) independently extracted data using a form developed by the Cochrane Effective Practice and Organisation of Care review group and modified and amended for this review. ${ }^{6}$

\section{Data synthesis and statistical analyses}

We conducted a meta-analysis of individual patient data in the subgroup of trials that evaluated specific outcomes in the more homogeneous populations described below. We contacted the investigators of trials with similar study populations and similar outcome measures by email or telephone, inviting them to contribute data. We sent up to 4 reminders.

Through our statistical analyses, we sought to include all patients who had been randomly assigned to a treatment group. We conducted these analyses on an intention-to-treat basis. When the individual patient data did not include the relevant outcomes, we relied on published data. For the metaanalysis of individual patient data, where at least 1 event was reported in both study groups in a trial, we used Cox regression models to calculate the log hazard ratio (HR) and its standard error for mortality and readmission separately for each data set. We included randomization group (avoidance of admission through provision of hospital care at home v. control), age (above or below the median) and sex in the models. The 
calculated $\log$ HRs were combined using fixed-effects inverse variance meta-analysis. ${ }^{7}$ We attempted to restrict the degree of heterogeneity between trials by pooling data from the trials that had recruited similar patient groups. We expressed the pooled effect as the HR for hospital-at-home programs compared with usual hospital care. We quantified heterogeneity by the Cochran $\mathrm{Q}^{8}$ and the $I^{2}$ statistic. ${ }^{9}$ If there were no events in one group, we used the Peto odds ratio (OR) method to calculate a log OR from the sum of the log-rank test "observed minus expected" statistics from a Kaplan-Meier survival analysis. This method does not require corrections for zero cell counts, and thus it performs well when events are rare. ${ }^{10} \mathrm{We}$ defined statistical significance at the 2-sided 5\% level $(p<0.05)$, and we present the data as the estimated effect with 95\% confidence intervals (CIs). For each comparison using published data for dichotomous outcomes, we calculated risk ratios using a fixed-effects model to combine data. Comparisons between health outcomes were restricted by the different measurement tools that were used in the included trials. We originally planned a direct comparison of costs, but ultimately did not attempt such a comparison because the trials used different methods to calculate costs.

In 2 data sets, ${ }^{11,12}$ some dates were missing for known events, so we assigned each missing event a time at the midpoint between randomization and last follow-up or the midpoint between follow-up times if these were known. For 1 of these trials, ${ }^{11}$ in which the follow-up period was 90 days, there were 4 cases in which we knew death had occurred but we did not have the date of death. We set the time to event as 45 days for the 3 cases in the group of patients who received hospital care at home and for the single case in the control group. In addition, there were 46 cases in which we knew that the patient had been readmitted, but we did not have a date for the event. We set the time to event as 45 days for the 31 cases in the group of patients who received hospital care at home and for the 15 cases in the control group. For the other trial, ${ }^{12}$ we used a time to event of 14 days if the patient was known to have died at some time between randomization and the 1-month follow-up or 59 days if the patient was known to have died between 1 and 3 months follow-up.

We used sensitivity analyses to assess the impact of the increased "exposure" time to readmission for the group receiving hospital care at home compared with the group receiving inpatient care. We calculated a pooled estimate both including and excluding transfers or readmissions to hospital occurring within the first 14 days, as this was the average duration that inpatients spent in hospital. For the 2 studies for which missing data were imputed, we undertook sensitivity analyses (assigning best-case and worst-case scenarios to the intervention and comparison groups) to assess the likely effect of such imputation.

\section{Results}

\section{Search results}

Electronic searching yielded a total of 2186 citations, of which 10 trials $^{11-20}$ (with a total of 1327 participants) were eligible for inclusion in the systematic review (Figure 1, Appendix 2 (available at www.cmaj.ca/cgi/content/full/180/2
/175/DC2). The 10 trials were from 4 countries: Australia, Italy, New Zealand and the United Kingdom. One trial had 3 arms, comparing inpatient care in a stroke unit, inpatient care provided by a stroke team and hospital care provided at home. ${ }^{12}$ We selected the patients receiving care from an inpatient stroke team as the comparison group, as this was most similar to the comparator in the other trials. Seven of the 10 studies were deemed to have similar study populations. We invited the investigators of these trials, which had recruited a total of 969 participants, to contribute data to the meta-analysis of individual patient data. ${ }^{11-13,15-17,20}$ The investigators for 5 of the 7 trials contributed data for a total of

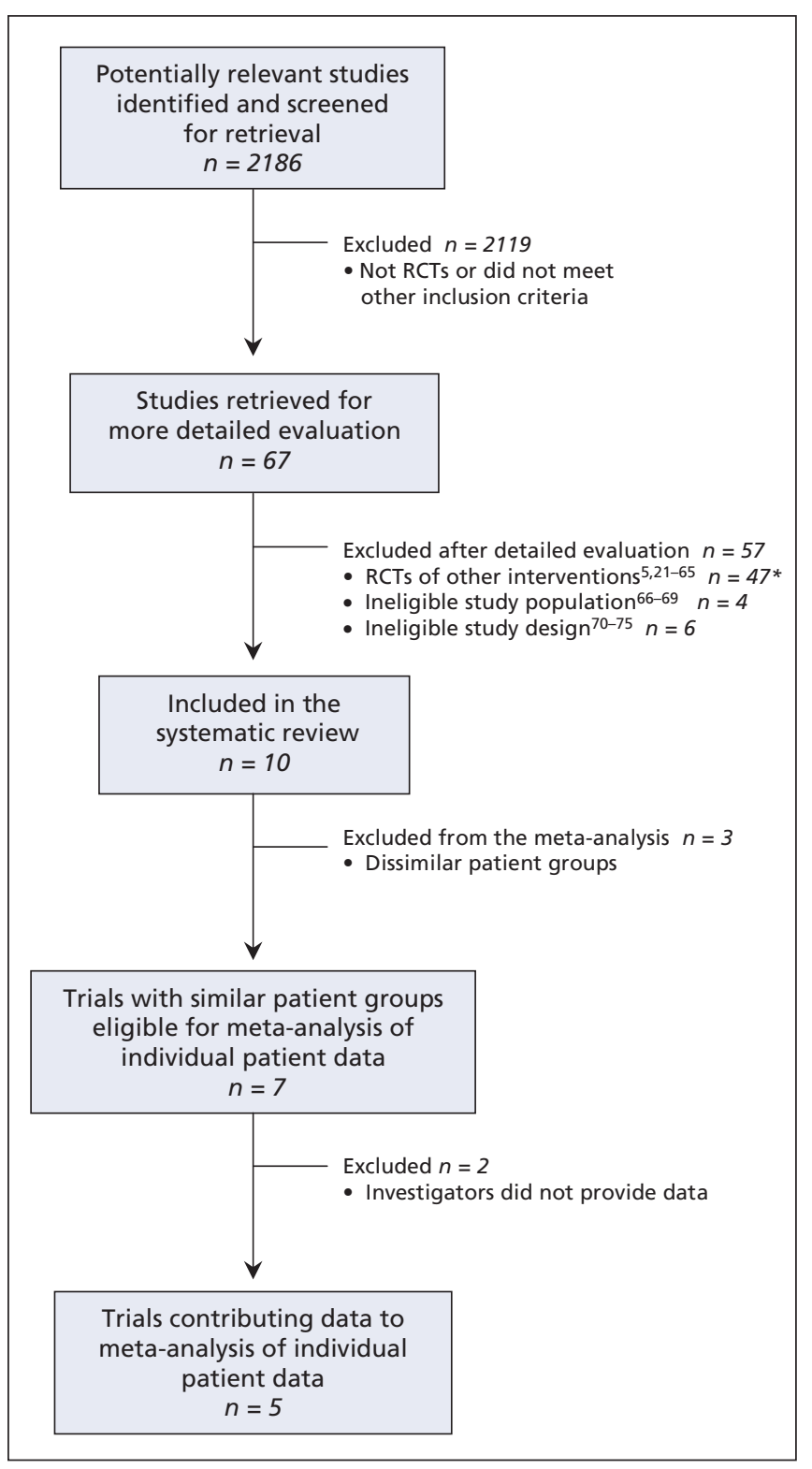

Figure 1: Quality of Reporting of Meta-analysis (QUOROM) flow chart showing the number of studies screened and included in the meta-analysis for avoiding admission through a hospital-athome program. *The randomized controlled trials (RCTs) of other interventions also included 1 unpublished trial by Dey, Woodman and the Manchester FASTER Trial Group. 
$844(87 \%)$ of the 969 participants..$^{11,12,15,17,20}$ One trialist could not be contacted ( $n=25$ participants),${ }^{16}$ and another declined to participate ( $n=100$ participants). ${ }^{13}$ Follow-up times ranged from 1 week to 12 months across all 10 of the trials.

\section{Study characteristics}

Trials included in the systematic review involved patients with chronic obstructive pulmonary disease, ${ }^{11,16}$ patients recovering from a moderately severe stroke who were clinically stable, ${ }^{12,17}$ and older patients with an acute medical condition. ${ }^{13,15,20}$ In addition, there was one trial each for patients with cellulitis, ${ }^{14}$ patients with community-acquired pneumonia ${ }^{18}$ and frail elderly patients with dementia. ${ }^{19}$ We included these 3 trials (with a total of 358 participants) in the systematic review but excluded them from the meta-analysis of individual patient data because the participants differed substantially from the populations in the other trials, by virtue of having an acute, short-term condition or significant cognitive impairment.

In 7 of the trials, staff in the emergency department transferred the patients to the hospital-at-home program. ${ }^{11,13,14,16-19}$ In the other 3 trials, the patients were managed directly from the community following referral by the primary care physician. ${ }^{12,15,20}$ A hospital outreach team, ${ }^{13,15,17,19}$ a mix of outreach and community staff $f^{11,12,16}$ or the general practitioner and community nursing staff ${ }^{14,18,20}$ provided care to patients who were receiving hospital care at home. In 2 trials, an independent association of general practitioners provided the intervention..$^{14,18}$

Six of the interventions included physiotherapy,,$^{12,15-17,19,20}$ and 4 of the interventions included occupational therapy. ${ }^{12,15,16,20}$ In 6 of the interventions, ${ }^{11,12,15,17,19,20}$ a social worker was part of the team providing hospital care at home. Three of the reports described access to a speech therapist as part of the intervention. ${ }^{12,17,20}$ One trial included access to a "cultural link worker" ${ }^{20}$ to help with language barriers and to ensure the provision of culturally sensitive services.

\section{Assessment of methodologic quality}

The method of randomization and concealment of allocation were adequate in 6 of the trials. ${ }^{12-15,18,20}$ Nine of the trials col- lected baseline data. In the other trial, which focused exclusively on comparing the costs of the interventions, collection of baseline data was not relevant. ${ }^{16}$ All of the trials used reliable measures of outcome, and blinded assessment of outcome was not possible. The majority of trials provided only a partial description of the type of care provided to the control group.

\section{Outcomes}

\section{Mortality}

We combined individual patient data for the 5 trials that recorded the time to death at 3 months' follow-up ( $n=835$ patients $)^{11,12,15,17,20}$ and for the 3 trials with 6 months' follow-up ( $n=607$ patients), ${ }^{12,17,20}$ adjusted for age and sex. After 3 months, mortality was lower, but not significantly so, for patients who were receiving hospital care at home (HR 0.77, 95\% CI $0.54-1.09, p=0.15$ ) (Figure 2). The difference in mortality was statistically significant after 6 months (HR $0.62,95 \%$ CI $0.45-0.87, p=0.005$ ) (Figure 3 ). A sensitivity analysis of the effect of imputing missing dates, in which we assigned the best-case and worst-case scenarios to the intervention and comparison groups, made little difference to the overall effect. $^{2}$ In the trial comparing inpatient stroke unit care, inpatient stroke team care and avoidance of admission through provision of hospital care at home, mortality at 3 months was significantly lower for those assigned to receive care in a stroke unit than for those who received hospital care at home (OR 0.41, 95\% CI 0.17-0.98). The difference was nonsignificant at 6 months (OR $0.50 ; 95 \%$ CI $0.25-1.02) .{ }^{12}$

\section{Transfer to hospital}

We combined data from 3 trials ( $n=416$ patients $)^{11,15,20}$ recording a transfer to hospital from the hospital-at-home program or readmission to hospital during a 3-month follow-up period, adjusted for age and sex. Admissions were greater, but not significantly so, for patients assigned to receive hospital care at home (HR 1.49, 95\% CI 0.96-2.33) (Figure 4). This result did not change when we removed admissions that occurred within 14 days of randomization (HR 1.42, 95\% CI 0.87-2.30).

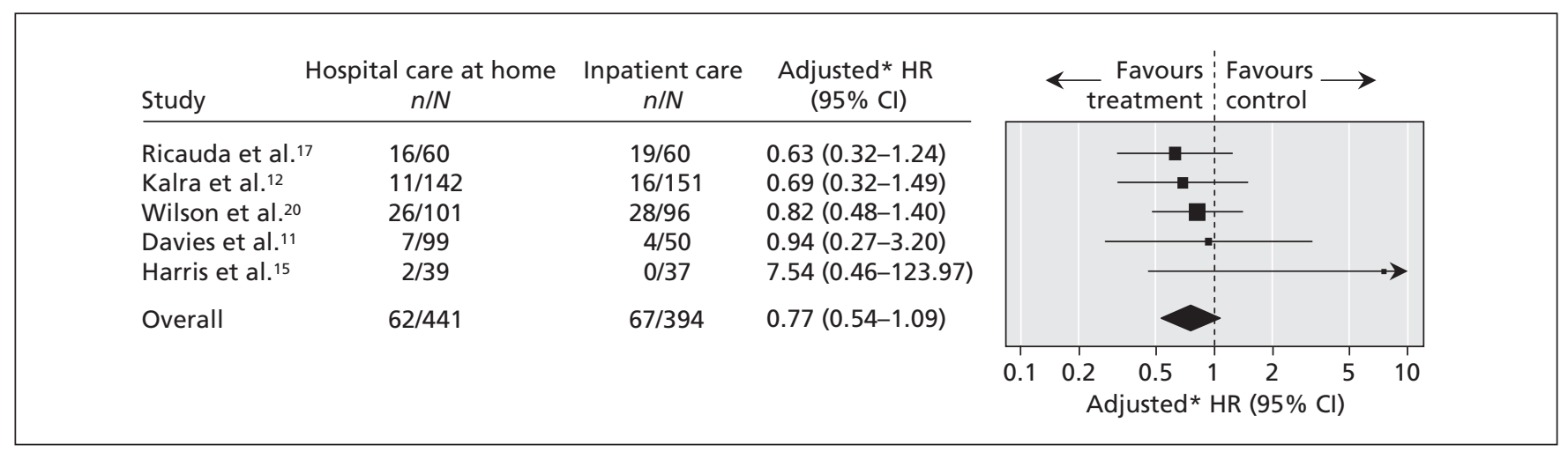

Figure 2: Fixed-effects meta-analysis of individual patient data: mortality at 3 months. *Adjusted for age and sex. The $N$ values represent the numbers of participants for which the trialists provided follow-up data (at our request); in some cases these values were less than the numbers of participants initially recruited (as stated in Appendix 2, available at www.cmaj.ca/cgi/content/full/180/2/175/DC2). Note: $\mathrm{Cl}=$ confidence interval, $\mathrm{HR}=$ hazard ratio. 


\section{Functional ability and well-being}

Five trials measuring functional ability reported nonsignificant differences for most measures at 3, 6 and 12 months. ${ }^{11,12,15,17,20}$ Caplan and associates ${ }^{13,76}$ reported a significant improvement on the Instrumental Activities of Daily Living score between admission and discharge for those assigned to receive hospital care at home (mean difference 0.57, $p=0.04$ ), but detected no changes on the Barthel Index, which measures activities of daily living. ${ }^{77}$ The Instrumental Activities of Daily Living score has a maximum value of 12 points and measures independent living skills, which may be difficult to measure in a hospital setting. ${ }^{78}$ In the trial involving patients with dementia, ${ }^{19}$ fewer patients assigned to receive hospital care at home had problems with sleep (difference 34 percentage points, $p<0.001$ ), agitation and aggression (difference 32.5 percentage points, $p<0.001$ ) and feeding (difference $31.0 \%$, $p<0.001)$ after discharge. In addition, in 1 trial that recruited patients recovering from stroke, ${ }^{17}$ there was a significant difference on the Geriatric Depression Scale ${ }^{79}$ favouring those assigned to receive hospital care at home (median difference 7 points, on a scale of 0 to $30, p<0.001$ ).

\section{Patient satisfaction}

For each trial reporting patient satisfaction, those assigned to receive hospital care at home reported significantly higher levels of satisfaction across a range of different medical conditions. ${ }^{13,14,18,20}$ In the study of patients with cellulitis, ${ }^{14}$ more of the patients in the group receiving hospital care at home than those admitted to hospital reported greater satisfaction with their location of care (85/91 [93\%] v. 59/88 [67\%], $p<0.001)$. In the study of patients with community-acquired pneumonia, ${ }^{18} 40 \%(p<0.001)$ more of the patients assigned to receive hospital care at home reported that they were happy with their care. In 2 other trials, which recruited mainly elderly patients with a mix of medical conditions, those assigned to receive hospital care at home also reported greater satisfaction (median difference of 3 on an 18-point scale, $p<0.001 ; ;^{20}$ mean difference of 0.9 on a 4 -point scale, $p<0.001^{13}$ ). However, the response rate for the control group in the second of these trials was much lower than that for the group receiving hospital care at home (40\% v. $78 \%)$.
In 1 trial, a small proportion of patients (6/101 [6\%]) refused hospital care at home and were admitted to hospital. In the same trial, a greater proportion assigned to receive hospital care (23/97 [24\%]) were not admitted because of refusal by the patient, caregiver or general practitioner. ${ }^{20}$

\section{Clinical outcomes}

In 1 trial ${ }^{13}$ fewer patients assigned to receive hospital care at home reported bowel complications (difference -22.5 percentage points, $95 \% \mathrm{CI}-34.0$ to -10.8 percentage points) or urinary complications (difference -14.4 percentage points, $95 \%$ CI -25.4 to -3.3 percentage points). In another trial, ${ }^{19}$ fewer patients assigned to receive hospital care at home had prescriptions for antipsychotic drugs at discharge (difference -14.0 percentage points, $95 \% \mathrm{CI}-28.0$ to 0.3 percentage points).

\section{Cost}

In the trials included in this review, investigators reported cost data, from the perspective of the health service, for different financial years and in different currencies, and used different methods to calculate the costs of resources used (Appendix 3, available at www.cmaj.ca/cgi/content/full/180/2 /175/DC2). One trial also took the perspective of the informal caregivers..$^{80}$ In general, costs were lower for patients assigned to receive hospital care at home than for those who received inpatient care. In 2 of the trials, the investigators conducted a full economic analysis. In 1 of these trials, when the costs of informal care were excluded, the provision of hospital care at home was significantly less expensive than admission to an acute care hospital for patients recovering from stroke. ${ }^{12,80} \mathrm{In}$ the other trial, costs were significantly less for patients who received hospital care at home when the analysis was restricted to treatment actually received..$^{20,81}$

\section{Length of stay}

The difference in length of stay in hospital varied among trials, ranging from a mean of 13.40 days less $(95 \% \mathrm{CI}$ -17.92 to -8.88$)^{20}$ to a mean of 5.06 days less $(95 \%$ CI -9.23 to $-0.89, p<0.02)^{15}$ for patients who received hospital care at home. In 1 trial, 51 of the 149 patients receiving hospital care at home were admitted to hospital, and these patients had a

\footnotetext{
(1)

\begin{tabular}{|c|c|c|c|c|c|}
\hline Study & $\begin{array}{l}\text { Hospital care at home } \\
n / N\end{array}$ & $\begin{array}{c}\text { Inpatient care } \\
n / N\end{array}$ & $\begin{array}{l}\text { Adjusted* HR } \\
(95 \% \mathrm{Cl})\end{array}$ & $\longleftarrow$ Favours & $\begin{array}{l}\text { Favours } \\
\text { control }\end{array}$ \\
\hline Wilson et al.20 & $30 / 101$ & $35 / 96$ & $0.68(0.42-1.12)$ & & \\
\hline Kalra et al. ${ }^{12}$ & $15 / 141$ & $24 / 149$ & $0.62(0.32-1.18)$ & $\square$ & \\
\hline Ricauda et al. ${ }^{17}$ & $18 / 60$ & $24 / 60$ & $0.54(0.29-1.01)$ & 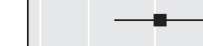 & \\
\hline \multirow[t]{3}{*}{ Overall } & $63 / 302$ & $83 / 305$ & $0.62(0.45-0.87)$ & & \\
\hline & & & & $0.10 .2 \quad 0.5$ & $\begin{array}{llll}1 & 2 & 5 & 10\end{array}$ \\
\hline & & & & Adjusted* & HR $(95 \% \mathrm{Cl})$ \\
\hline
\end{tabular}

Figure 3: Fixed-effects meta-analysis of individual patient data: mortality at 6 months. Adjusted for age and sex. The $N$ values represent the numbers of participants for which the trialists provided follow-up data (at our request); in some cases these values were less than the numbers of participants initially recruited (as stated in Appendix 2, available at www.cmaj.ca/cgi/content/full/180/2/175/DC2). Note: $\mathrm{Cl}=$ confidence interval, $\mathrm{HR}=$ hazard ratio.
} 
mean length of stay of 48.6 (standard deviation [SD] 26.7) days. In contrast, the length of stay for the control group was 29.50 (SD 40.10) days (difference 19 days, $95 \%$ CI 7.2-31). ${ }^{12}$

Analysis of the 2 trials in which all days of care were accounted for (hospital care at home plus any inpatient days) showed that the total length of stay was lower for patients receiving hospital care at home than for those in the control group in 1 trial (difference -14.13 days, $95 \%$ CI -20.18 to $-7.08, p<0.02,{ }^{20}$ but was greater in the other trial (difference 15.90 days, $95 \%$ CI 8.10 to $23.70, p<0.001) .{ }^{17}$

\section{Place of residence after discharge}

In 2 trials, more of the patients assigned to inpatient hospital care were living in an institutional setting compared with those assigned to receive hospital care at home (relative risk [RR] $0.11,95 \%$ CI $0.03-0.46, p<0.002$ at discharge, in a study of elderly patients with dementia; ${ }^{19}$ RR $0.19,95 \%$ CI 0.06 to $0.61, p<0.005$ at 6 months' follow-up in a study of patients recovering from stroke ${ }^{17}$ ). In another trial involving patients recovering from stroke, ${ }^{12}$ there was no significant difference between the groups in the proportion of patients living in an institutional setting at 6 months follow-up (RR 1.29, 95\% CI 0.63-2.67, $p=0.49$ ).

\section{Caregiver outcomes}

In 1 trial, the investigators explored caregiver satisfaction through semistructured interviews. ${ }^{20}$ Caregivers reported that although admission to hospital would potentially have relieved them of the burden associated with caring for the patient, the upheaval of visiting the patient in hospital and the accompanying anxiety made this a less satisfactory option.

\section{Interpretation}

In this systematic review of avoidance of admission through the provision of hospital care at home, we included 10 trials involving elderly patients with a medical condition. For 5 of these trials, ${ }^{11,12,15,17,20}$ we obtained individual patient data for meta-analysis, representing $87 \%$ of potentially eligible patients. We performed meta-analyses where there was sufficient similarity among the trials and where common out- comes had been measured. Although there were no differences between groups for most measures of functional ability or quality of life, patients assigned to receive hospital care at home had a significantly lower risk of death at 6 months' follow-up. The reduction in risk was not significant at 3 months' follow-up, which may reflect the lower number of events by that time point. However, the direction of effect was consistent between trials and for each follow-up period. The patients reported high levels of satisfaction and expressed a preference for being treated at home.

The results of our meta-analysis of individual patient data should not be taken as evidence that hospital care is hazardous. Rather, we believe they show that there is no evidence to suggest that avoiding admission through provision of hospital care at home leads to greater mortality. One difficulty lies in determining which groups of patients studied in this review are most likely to benefit from avoidance of admission through provision of hospital care at home and to which other groups these results might apply. The patients recruited to the trials that were included in the meta-analysis were elderly patients with a medical event or condition, including stroke and chronic obstructive pulmonary disease, that would usually require admission to hospital. The average age of the populations studied ranged from 70 to over 80 years. The entry criteria required patients to be clinically stable and not requiring diagnostic investigation by a specialist or emergency interventions. Furthermore, in each of the trials, patients whose condition unexpectedly deteriorated and those who could no longer be cared for at home had access to hospital admission. Another concern is that we cannot rule out the existence of publication bias, which could mean that some trials that would have been eligible for our review remained unknown to us because their publication or availability was influenced by their results.

There was some variation in the way the schemes providing hospital care at home operated. In 3 studies, the schemes admitted patients directly from the community. ${ }^{12,15,20}$ In the other 7 trials, the services operated from an emergency department. ${ }^{11,13,14,16-19}$ Only 3 trials evaluated interventions where the patient could be living alone. Nonetheless, the trials had some important features in common, including coordination

\begin{tabular}{|c|c|c|c|c|c|}
\hline Study & $\begin{array}{c}\text { Hospital care at home } \\
n / N\end{array}$ & $\begin{array}{c}\text { Inpatient care } \\
n / N\end{array}$ & $\begin{array}{c}\text { Adjusted* HR } \\
(95 \% \mathrm{Cl}) \\
\end{array}$ & \multicolumn{2}{|c|}{$\longleftarrow \begin{array}{r:l}\text { Favours } & \text { Favours } \\
\text { treatment } & \text { control }\end{array}$} \\
\hline Wilson et al. ${ }^{20}$ & $21 / 101$ & $11 / 96$ & $1.81(0.87-3.75)$ & & 1 \\
\hline Davies et al. ${ }^{11}$ & $41 / 93$ & $17 / 50$ & $1.32(0.74-2.34)$ & & \\
\hline Harris et al. ${ }^{15}$ & $2 / 39$ & $1 / 37$ & $1.61(0.13-19.71)$ & - & $\rightarrow$ \\
\hline Overall & $64 / 233$ & 29/183 & $1.49(0.96-2.33)$ & & \\
\hline & & & & $\begin{array}{l}0.2 \quad 0.5 \\
\text { Adjusted* }\end{array}$ & $\begin{array}{lll}1 & 2 & 5 \\
H R & (95 \% \mathrm{Cl})\end{array}$ \\
\hline
\end{tabular}

Figure 4: Fixed-effects meta-analysis of individual patient data: transfers to hospital at 3 months. *Adjusted for age and sex. The $N$ values represent the numbers of participants for which the trialists provided follow-up data (at our request); in some cases these values were less than the numbers of participants initially recruited (as stated in Appendix 2, available at www.cmaj.ca/cgi/content/full /180/2/175/DC2). Note: $\mathrm{Cl}=$ confidence interval, $\mathrm{HR}$ = hazard ratio. 
of care by a multidisciplinary team, provision of 24-hour coverage if required (with access to a doctor) and a safe home environment. Although schemes for avoiding admission through provision of hospital care at home offer an alternative to inpatient admission for some patients, the numbers of patients recruited to the trials included in our study were low, and some of these patients required access to hospital services. This would make closure of a ward or hospital in favour of providing hospital care at home an unrealistic option. Hospital length of stay varied among the trials included in this review, which may reflect the patients' health problems and the local organization of health care. Even so, the shorter length of stay for patients receiving hospital care at home would release hospital beds. Alternatively, schemes to avoid admission through provision of hospital care at home may be offered as a supplement to existing services, which might be an acceptable policy option for some groups of patients.

\section{Conclusion}

Over the past 10 years, the evidence from randomized controlled trials for avoiding admission through the provision of hospital care at home has grown substantially, from 1 to 10 trials ${ }^{82}$ despite the practical difficulties of conducting randomized controlled trials of service innovations. Although each of the trials in our systematic review was underpowered, together they provide sufficient power to reveal important differences in mortality. In addition, obtaining individual patient data allowed us to conduct a time-to-event analysis. Future trials of schemes to avoid admission through provision of hospital care at home should measure mortality and readmission, with particular attention to the transfer of patients between these programs and inpatient care. To facilitate the application of evidence, clinical and dependency data of recruited patients should be collected using standardized measures. Research should also include a formal, planned economic analysis using costs that are sensitive to the different resources used during an episode of care. The role of advanced portable medical devices and communication technologies in providing hospital care at home should be explored in pilot studies. These should help to determine the feasibility, acceptability and possible impact that these types of interventions could have on health care systems.

This article has been peer reviewed.

Competing interests: Five of the authors (Robert Angus, Lalit Kalra, Nicoletta Aimonino Ricauda, Vittoria Tibaldi, Andrew Wilson) contributed trial data to the meta-analysis of individual patient data. None declared for Sasha Shepperd, Helen Doll, Mike Clarke, and Steve Iliffe.

Contributors: Sasha Shepperd contributed substantially to the conception and design of the review, the acquisition of the data, and the analysis and interpretation of data. She drafted the article and gave final approval of the version to be published. Helen Doll and Mike Clarke contributed substantially to the design of the review and to the analysis and interpretation of the data. Steve Iliffe contributed to the conception of the review and acquisition of the data. Helen Doll, Mike Clarke, Steve Iliffe, Robert Angus, Lalit Kalra, Nicoletta Aimonino Ricauda, Vittoria Tibaldi and Andrew Wilson contributed substantially to the acquisition of data, critically commented on a draft of the article and gave final approval of the version to be published.
Acknowledgements: We thank Dr. Roger Harris and Joanne Broad for contributing data from the New Zealand trial to the meta-analysis of individual patient data.

Funding: No external funding was received for this research.

\section{REFERENCES}

1. Brennan TA, Leape LL, Laird NM, et al. Incidence of adverse events and negligence in hospitalized patients: results of the Harvard Medical Practice Study I 1991. Qual Saf Health Care 2004;13:145-51.

2. Shepperd S, Doll H, Angus RM, et al. Admission avoidance hospital at home Cochrane Database Syst Rev 2008;(4):CD007491.

3. Parker G, Bhakta P, Lovett CA, et al. A systematic review of the costs and effectiveness of different models of paediatric home care. Health Technol Assess 2002; 6:iii-108.

4. Shepperd S, Doll H, Gowers S, et al. Alternatives to inpatient mental health care for children and young people (protocol). Cochrane Database Syst Rev 2007;(4): CD006410.

5. Wolfe CDA, Tilling K, Rudd AG. The effectiveness of community based rehabilitation for stroke patients who remain at home: a pilot randomised trial. Clin Rehabil 2000;14:563-9.

6. Cochrane Effective Practice and Organisation of Care Group. Data Abstraction Form. Ottawa (ON): The Group; 2002. Available: www.epoc.cochrane.org/Files /Website/Reviewer\%20Resources/Data\%20Abstraction\%20Form\%20-\%20EPOC \%20-\%202007-Feb-27.doc (accessed 2008 Dec. 19).

7. Deeks JJ, Altman D, Bradburn MJ. Statistical methods for examining heterogeneity and combining results from several studies in meta-analysis. In: Egger M, Davey Smith G, Altman DG, editors. Systematic reviews in health care. Metaanalysis in context. London (UK): BMJ; 2001. p. 285-312.

8. Cochran WG. The combination of estimates from different experiments. Biomet rics 1954;10:101-29.

9. Higgins JPT, Thompson SG, Deeks JJ, et al. Measuring inconsistency in metaanalysis. BMJ 2003;327:557-60.

10. Bradburn MJ, Deeks JJ, Berlin JA, et al. Much ado about nothing: a comparison of the performance of meta-analytical methods with rare events. Proceedings of the 6th Cochrane Colloquium; 1998 Oct 22-26; Baltimore (MD). The Cochrane Collaboration; 1998.

11. Davies L, Wilkinson M, Bonner S, et al. Hospital at home versus hospital care in patients with exacerbations of chronic obstructive pulmonary disease: prospective randomised controlled trial. BMJ 2000;321:1265-8.

12. Kalra L, Evans A, Perez I, et al. Alternative strategies for stroke care: a prospective randomised controlled trial. Lancet 2000;356:894-9.

13. Caplan GA, Ward JA, Brennan NJ, et al. Hospital in the home: a randomised controlled trial. Med J Aust 1999;170:156-60.

14. Corwin P, Toop L, McGeoch G, et al. Randomised controlled trial of intravenous antibiotic treatment for cellulitis at home compared with hospital. BMJ 2005;330:129.

15. Harris R, Ashton T, Broad J, et al. The effectiveness, acceptability and costs of a hospital-at-home service compared with acute hospital care: a randomized controlled trial. J Health Serv Res Policy 2005;10:158-66.

16. Nicholson C, Bowler S, Jackson C, et al. Cost comparison of hospital- and homebased treatment models for acute chronic obstructive pulmonary disease. Aust Health Rev 2001;24:181-7.

17. Ricauda NA, Bo M, Molaschi M, et al. Home hospitalization service for acute uncomplicated first ischemic stroke in elderly patients: a randomized trial. $J$ Am Geriatr Soc 2004;52:278-83.

18. Richards DA, Toop LJ, Epton MJ, et al. Home management of mild to moderately severe community-acquired pneumonia: a randomised controlled trial. Med J Aust 2005; $183: 235-8$

19. Tibaldi V, Aimonino N, Ponzetto M, et al. A randomized controlled trial of a home hospital intervention for frail elderly demented patients: behavioral disturbances and caregiver's stress. Arch Gerontol Geriatr Suppl 2004;(9):431-6.

20. Wilson A, Parker H, Wynn A, et al. Randomised controlled trial of effectiveness of Leicester hospital at home scheme compared with hospital care. BMJ 1999;319: $1542-6$.

21. Adler MW, Waller JJ, Creese A, et al. Randomised controlled trial of early discharge for inguinal hernia and varicose veins. J Epidemiol Community Health 1978;32:136-42.

22. Anderson C, Rubenach S, Mhurchu CN, et al. Home or hospital for stroke rehabilitation? results of a randomized controlled trial: I: health outcomes at 6 months. Stroke 2000;31:1024-31.

23. Askim T, Rohweder G, Lydersen S, et al. Evaluation of an extended stroke unit service with early supported discharge for patients living in a rural community. A randomized controlled trial. Clin Rehabil 2004;18:238-48.

24. Bautz-Holtert E, Sveen U, Rygh J, et al. Early supported discharge of patients with acute stroke: a randomized controlled trial. Disabil Rehabil 2002;24:348-55.

25. Booth JE, Roberts JA, Flather M, et al. A trial of early discharge with homecare compared to conventional hospital care for patients undergoing coronary artery bypass grafting. Heart 2004;90:1344-5.

26. Caplan GA, Coconis J, Board N, et al. Does home treatment affect delirium? A randomised controlled trial of rehabilitation of elderly and care at home or usual 
treatment (The REACH-OUT trial). Age Ageing 2006;35:53-60.

27. Cotton MM, Bucknall CE, Dagg KD, et al. Early discharge for patients with exacerbations of chronic obstructive pulmonary disease: a randomized controlled trial. Thorax 2000;55:902-6.

28. Crotty $\mathrm{M}$, Whitehead $\mathrm{CH}$, Gray S, et al. Early discharge and home rehabilitation after hip fracture achieves functional improvements: a randomized controlled trial. Clin Rehabil 2002;16:406-13

29. Cunliffe AL, Gladman JRF, Husbands SL, et al. Sooner and healthier: a randomised controlled trial and interview study of an early discharge rehabilitation service for older people. Age Ageing 2004;33:246-52.

30. Donald IP, Baldwin RN, Bannerjee M. Gloucester hospital-at-home: a randomized controlled trial. Age Ageing 1995;24:434-9.

31. Donnelly M, Power M, Russell M, et al. Randomised controlled trial of an early discharge rehabilitation service: the Belfast community stroke trial. Stroke 2004; 35:127-33.

32. Indredavik B, Fjaertoft H, Ekeberg G, et al. Benefit of an extended stroke unit service with early supported discharge: a randomized, controlled trial. Stroke 2000; 31:2989-94.

33. Martin F, Oyewole A, Moloney A. A randomized controlled trial of a high support hospital discharge team for elderly people. Age Ageing 1994;23:228-34.

34. Mayo NE, Wood-Dauphinee S, Cote R, et al. There's no place like home: an evaluation of early supported discharge for stroke. Stroke 2000;31:1016-23.

35. Ojoo JC, Moon T, McGlone S, et al. Patients' and carers' preferences in two models of care for acute exacerbations of COPD: results of a randomised controlled trial. Thorax 2002;57:167-9.

36. Palmer Hill S, Flynn J, Crawford EJP. Early discharge following total knee replacement - a trial of patient satisfaction and outcomes using an orthopaedic outreach team. J Orthop Nurs 2000;4:121-6.

37. Richards SH, Coast J, Gunnell DJ, et al. Randomised controlled trial comparing effectiveness and acceptability of an early discharge, hospital at home scheme with acute hospital care. BMJ 1998;316:1796-801

38. Rodgers H, Soutter J, Kaiser W, et al. Early supported hospital discharge following acute stroke: pilot study results. Clin Rehabil 1997;11:280-7.

39. Ruckley CV, Cuthbertson C, Fenwick N, et al. Day care after operations for hernia or varicose veins: a controlled trial. Br J Surg 1978;65:456-9.

40. Rudd AG, Wolfe CD, Tilling K, et al. Randomised controlled trial to evaluate early discharge scheme for patients with stroke. BMJ 1997;315:1039-44.

41. Shepperd S, Harwood D, Jenkinson C, et al. Randomised controlled trial comparing hospital at home care with inpatient hospital care. I: three month follow up of health outcomes. BMJ 1998;316:1786-91.

42. Skwarska E, Cohen G, Skwarski KM, et al. Randomized controlled trial of supported discharge in patients with exacerbations of chronic obstructive pulmonary disease. Thorax 2000;55:907-12.

43. Suwanwela NC, Phanthumchinda K, Limtongkul S, et al.; Thai Red Cross Volunteers Bureau. Comparison of short (3-day) hospitalization followed by home care treatment and conventional (10-day) hospitalization for acute ischemic stroke. Cerebrovasc Dis 2002;13:267-71.

44. Widen-Holmqvist L, von Koch L, Kostulas V, et al. A randomized controlled trial of rehabilitation at home after stroke in southwest Stockholm. Stroke 1998;29:591-7.

45. Cummings JE, Hughes SL, Weaver FM, et al. Cost-effectiveness of Veterans Administration hospital-based home care. A randomized clinical trial. Arch Intern Med 1990;150:1274-80.

46. Hansen FR, Spedtsberg K, Schroll M. Geriatric follow-up by home visits after discharge from hospital: a randomized controlled trial. Age Ageing 1992;21:445-50.

47. Hedrick SC, Inui TS. The effectiveness and cost of home care: an information synthesis. Health Serv Res 1986;20:851-80.

48. Hermiz O, Comino E, Marks G, et al. Randomised controlled trial of home based care of patients with chronic obstructive pulmonary disease. BMJ 2002;325:938

49. King MT, Hall J, Caleo S, et al. Home or hospital? An evaluation of the costs, preferences and outcomes of domiciliary chemotherapy. Int J Health Serv 2000;30:557-79.

50. Koopman MM, Prandoni P, Piovella F, et al. Treatment of venous thrombosis with intravenous unfractionated heparin administered in the hospital as compared wtih subcutaneous low-molecular-weight heparin administered at home. The Tasman Study Group. N Engl J Med 1996;334:682-7.

51. Levine M, Gent M, Hirsh J, et al. A comparison of low-molecular-weight heparin administered primarily at home with unfractionated heparin administered in the hospital for proximal deep-vein thrombosis. N Engl J Med 1996;334:677-81.

52. Magid DM, Vokes EE, Schilsky RL, et al. A randomized study of inpatient versus outpatient continuous intravenous infusion chemotherapy: psychosocial aspects. Sel Cancer Ther 1989;5:137-45.

53. Melin AL, Bygren LO. Efficacy of the rehabilitation of elderly primary health care patients after short-stay hospital treatment. Med Care 1992;30:1004-15.

54. Melin AL. A randomized trial of multidisciplinary in-home care for frail elderly patients awaiting hospital discharge. Aging (Milano) 1995;7:247-50.
55. Pozzilli C, Brunetti M, Amicosante AMV, et al. Home based management in multiple sclerosis: results of a randomised controlled trial. J Neurol Neurosurg Psychiatry 2002;73:250-5.

56. Rischin D, White MA, Matthews JP, et al. A randomised controlled trial of chemotherapy in the home: patient preferences and cost analysis. Med J Aust 2000;173:125-7.

57. Romano L, Minicucci L, Spallone E, et al. [Role of home therapy with ofloxacin in patients with cystic fibrosis (CF)]. G Ital Chemioter 1991;38:181-3. Italian.

58. Ronning OM, Guldvog B. Outcome of subacute stroke rehabilitation: a randomized controlled trial. Stroke 1998;29:779-84

59. Smith AG, Soutar RL, Schey S, et al. Home care versus hospital care in patients with multiple myeloma treated with pamidronate. Int J Palliat Nurs 2004;10:144-9.

60. Williams PL, Crawley JC, Freeman AM, et al. Feasibility of outpatient management after intra-articular yttrium-90: comparison of two regimens. BMJ 1981 282:13-4.

61. Wong FK, Mok MP, Chan T, et al. Nurse follow-up of patients with diabetes: randomized controlled trial. J Adv Nurs 2005;50:391-402.

62. Zimmer JG, Groth-Juncker A, McCusker J. Effects of a physician-led home care team on terminal care. J Am Geriatr Soc 1984;32:288-92.

63. Zimmer JG, Groth Juncker A, McCusker J. A randomized controlled study of home health care team. Am J Public Health 1985;75:134-41

64. Bonnema J, Van Wersch A, van Geel A, et al. Cost of care in a randomised trial of early hospital discharge after surgery for breast cancer. Eur J Cancer 1998;34: 2015-20.

65. Bundred N, Maguire P, Reynolds J, et al. Randomised controlled trial of effects of early discharge after surgery for breast cancer. BMJ 1998:317:1275-9.

66. Brooten D, Kumar S, Brown LP, et al. A randomized clinical trial of early hospital discharge and home follow-up of very-low-birth-weight infants. NLN Pub 1987;(21-2194):95-106.

67. Brooten D, Roncoli M, Finkler S, et al. A randomized trial of early hospital discharge and home follow- up of women having cesarean birth. Obstet Gynecol 1994;84:832-8.

68. Hill JD, Hampton JR, Mitchell JR. A randomised trial of home-versus-hospital management for patients with suspected myocardial infarction. Lancet 1978;1:837-41.

69. Mather HG, Morgan DC, Pearson NG, et al. Myocardial infarction: a comparison between home and hospital care for patients. BMJ 1976;1:925-9.

70. Gerson LW, Berry AF. Psycho-social effects of home care: results of a randomized controlled trial. Int J Epidemiol 1976;5:159-65.

71. Hernandez C, Casas A, Escarrabill J, et al.; CHRONIC Project. Home hospitalisation of exacerbated chronic obstructive pulmonary disease patients. Eur Respir J 2003; 21:58-67.

72. Klettke U, Magdorf K, Staab D, et al. [Ambulatory vs. inpatient intravenous antibiotic therapy in mucoviscidosis patients - a controlled study]. Mabulante vs stationare intravenose antibiotische Therapie bei Mukoviszidosepatienten. Pneumologie 1999;53:31-6. German.

73. Stone JR, Patterson E, Felson L. The effectiveness of home care for general hospital patients. JAMA 1968;205:145-8

74. Wade DT, Langton Hewer R, Skilbeck CE, et al. Controlled trial of a home-care service for acute stroke patients. Lancet 1985;1:323-6.

75. Wolter JM, Cagney RA, McCormack JG. A randomized trial of home vs hospital intravenous antibiotic therapy in adults with infectious diseases. $J$ Infect 2004;48:263-8.

76. Caplan GA, Coconis J, Woods J. Effect of hospital in the home treatment on physical and cognitive function: a randomized controlled trial. J Gerontol A Biol Sci Med Sci 2005;60:1035-8.

77. Mahoney FI, Barthel DW. Functional evalution: the Barthel index. Md Med J $1965 ; 14: 61-5$

78. Lawton MP, Brody EM. Assessment of older people: self-maintaining and instrumental activities of daily living. Gerontologist 1969;9:179-186.

79. Brink TL, Yesavage JA, Heersema PH, et al. Screening tests for geriatric depression. Clin Gerontol 1982;1:37-45.

80. Patel A, Knapp M, Perez I, et al. Alternative strategies for stroke care: cost-effectiveness and cost-utility analyses from a prospective randomized controlled trial. Stroke 2004;35:196-203.

81. Jones J, Wilson A, Parker H, et al. Economic evaluation of hospital at home versus hospital care: cost minimisation analysis of data from randomised controlled trial. BMJ 1999;319:1547-50.

82. Shepperd S, Iliffe S. Hospital at home versus in-patient hospital care. Cochrane Database Syst Rev 2005;(2)CD000356.

Correspondence to: Dr. Sasha Shepperd, Public Health, University of Oxford, Old Road Campus, Headington, Oxford, oX37LF, United Kingdom; sasha.shepperd@dphpc.ox.ac.uk 